\title{
INOVAÇÕES CURRICULARES: O PONTO DE VISTA DE GESTORES DE ESCOLAS DO ENSINO BÁSICO EM PORTUGAL'
}

Preciosa Teixeira Fernandes*

RESUMO: Na última década, em Portugal, assistimos a alterações nas políticas curriculares para o ensino básico que têm contribuído para uma certa instabilidade no "terreno de ação" dos professores. Essas alterações ocorreram sobretudo desde o final da década de 1990, com o "Projecto de Gestão Flexível do Currículo" (GFC) e, em 2005/2006, com a medida "Escola a tempo inteiro". Do ponto de vista metodológico, sigo os contributos de Doyle e Ponder (1977) e de Correia (1989), sobre estratégias e processos de resistência ativa e passiva adotados por professores perante inovações centralizadas. À luz desses referentes, analiso discursos de professores/as em exercício de gestão e que experienciaram, enquanto tal, aquelas duas inovações. Em síntese, é intenção final deste texto situar o debate do lado micro da política curricular.

Palavras-chave: Inovação Curricular; Professores Gestores.

\section{CURRICULAR INNOVATIONS:}

THE PERSPECTIVE OF TEACHERS INVOLVED IN SCHOOL GOVERNANCE IN PORTUGAL

ABSTRACT: In the last decade in Portugal, there have been changes in the curriculum policies for Basic Education that have contributed to some instability in the "field of action" of teachers. These changes were felt mainly in the late 90s with the Project "Flexible Management of Curriculum" (GFC) and in 2005/2006 with the Full-time School measure. From the methodological point of view I have adopted the contributions of Doyle and Ponder (1977) and Correia (1989), concerning the strategies and processes of active and passive resistance shown by teachers towards central innovations. This is the base for my analysis of the speeches made by teachers who are directly involved in the daily governance of schools and have also experienced the two mentioned innovations. In short, the final intention of this text is to situate the debate on the micro side of the curriculum policies.

Keywords: Curricular Innovation; Governance Teachers'.

\footnotetext{
* Professora Auxiliar da Faculdade de Psicologia e de Ciências da Educação da Universidade do Porto (UP - Pontugal) e Investigadora do Centro de Investigação e Intervenção Educativas (CIIE) da Universidade do Porto (UP - Portugal). E-mail: preciosa@fpce.up.pt
} 


\section{Introdução}

A consideração em analisar políticas curriculares para o ensino Básico em Portugal, na dimensão de implementação no contexto da prática (BALL, 1992), no período de 1997 a 2006, decorre do fato de esse ser um período sinalizado por dois momentos distintos. O primeiro momento é marcado pela emergência, em 1997, de um movimento de flexibilização curricular que é materializado pelo projeto de "Gestão Flexível do Currículo"3 (GFC). Esse projeto, que teve a duração de quatro anos, assinala um marco histórico no campo das políticas curriculares, nomeadamente no que diz respeito à metodologia da sua implementação ${ }^{4} \mathrm{e}$ às concepções curriculares que o matriciam, finalizando seu estatuto de projeto, em 2001, com a regulamentação, pelo dec-lei n. 6/2001, de 18 de janeiro, da Reorganização Curricular do Ensino Básico (RCEB).

Nesse período de governação socialista (1995-2002), assiste-se a uma tendência de descentralização das políticas educacionais e curriculares expressa na valorização do local e na ênfase no papel dos professores e das escolas na configuração de processos de inovação curricular ${ }^{5}$. Apesar dessa ênfase e de se constatar certo abandono pelo conceito de reforma top-down, coexistem, contudo, nessa época, referências de forte apelo à inclusão e aos princípios de uma educação e formação ao longo da vida, por um lado, e, por outro, requerem-se processos competitivos para que se atinjam melhores resultados. Essa tensão entre a afirmação de princípios de uma escola democrática e a manutenção de princípios de uma escola meritocrática é visível nos discursos que enformam a referida Reorganização Curricular do Ensino Básico de final da década de 1990/início dos anos 2000 e foi, como procurarei aclarar neste texto, interpretada e vivida pelas escolas e pelos professores de diferentes maneiras.

No período entre o ano de 2002 e 2004, com o governo socialdemocrata, retoma-se uma orientação da política educacional de cariz centralista. Nas escolas, os professores veem-se desapoiados nas experiências que tinham em curso, e são confrontados com medidas avulsas que fazem estagnar os processos de inovação curricular.

O ano 2005-2006, que corresponde ao segundo momento a que reporto a análise, configura uma nova etapa de governação socialista. Trata-se de um período de políticas híbridas que apelam à promoção da 
escola pública como condição para a maior igualdade de oportunidades e de justiça social e que, simultaneamente, visam ao controlo social, através quer da avaliação aferida das aprendizagens dos alunos, quer da avaliação externa das instituições e, mais recentemente, pela avaliação de desempenho dos professores.

No propósito de cumprir o objetivo de situar a reflexão no plano micro da política curricular e, portanto, de dar voz ao contexto da prática (BALL, 1992), o presente texto tem como objetivo analisar discursos de professores sobre medidas curriculares concretas, implementadas em períodos distintos e inscritas em racionalidades também distintas. Clarificando, é intenção deste texto, a partir dos referenciais analíticos de Doyle e Ponder (1977) e de Correia (1989) sobre estratégias e processos de resistência de professores face a inovações curriculares com origem exterior às escolas, analisar o modo como um grupo de dez professores $/ \mathrm{as}^{6}$, em exercício de gestão, interpreta, na atualidade, o projeto de GFC (iniciado em 1997) e a consequente RCEB (dec. lei n. 6/001) e, mais recentemente, em 2005-2006, a medida "Escola a Tempo Inteiro".

Este texto inicia, portanto, com uma abordagem teórica sobre inovações curriculares, significados e lógicas que as têm caracterizado, e que constitui a base para reflexão sobre o papel dos professores face a inovações curriculares, que produzo no momento seguinte. Tal abordagem sustenta a análise focada nos "discursos diretos" de professores em exercício de gestão, que entrevistei, feita a partir dos contributos de Doyle e Ponder (1977) e de Correia (1989) e que constitui a segunda parte deste trabalho. Intento também, a partir do que designei de interpretações positivas e negativas e de advertência sobre as inovações curriculares em análise e que me são restituídas pelos discursos dos professores, contribuir para a ressignificação daquele quadro de análise. Por fim, teço algumas considerações que sistematizam as principais ideias e que levantam algumas interrogações sobre o papel dos "atores de terreno" na construção de inovações curriculares. 


\section{Inovações curriculares: significados e lógicas de ação}

De um modo geral, as inovações educativas e curriculares têm sido associadas a alterações econômicas, políticas, sociais e culturais da sociedade e a situações de crise do sistema, surgindo, assim, com finalidades e propósitos de solução para essa mesma crise e para os problemas que lhe estão na origem. Nesse sentido, têm sido várias as lógicas que as têm caracterizado, conforme se trate de inovações com cunho fortemente centralizado ou de inovações que canalizam o poder da Administração Central para os órgãos regionais e locais, assumindo, por isso, um cariz mais descentralizador. Nesse âmbito, têm sido também diversos os significados que lhes têm sido atribuídos. Para José Alberto Correia (1989, p. 31), inovação representa sempre "uma mudança deliberada e conscientemente assumida (...) visando objectivos bem precisos: a melhoria do sistema (e) o aumento da sua eficácia no cumprimento dos seus objectivos (...)". Nessa perspectiva, a inovação é sempre um processo planificado, e que visa a alcançar objetivos compatíveis com os do sistema e, nesse sentido, aproxima-se do sentido de reforma. Essa ótica encaixa-se na definição de lógicas de inovações centralizadas apresentada por Benavente (1992, p. 51) e caracterizadas por serem "formais, orientadas para a obtenção e avaliação de resultados quantificáveis", uniformes e inflexíveis e focadas em estruturas e suportes gerais. Essas significações de inovação, e lógicas que a caracterizam, estão muito próximas dos conceitos de mudança e de inovação referidos por Fernandes (2000). Na perspectiva dessa autora, o conceito de mudança é utilizado para "referir alterações provocadas por agentes internos ou externos, concretizadas de forma progressiva" ao passo que o conceito "de inovação educativa se utiliza para assinalar a ruptura com situações ou práticas anteriores” (p. 48). Nessa linha de proximidades de sentidos, Bolívar (2003, p. 50) alega que a "inovação educativa pertence a uma constelação ou universo semântico formado - pelo menos por estes quatro termos: mudança educativa ou curricular, reforma educativa, inovação educativa, movimento de renovação". Considera, por isso, questionável a associação que é feita, na cultura ocidental, entre mudança e "melhoria ou "progresso", argumentando que essa associação depende do que se pretende reformar, dos princípios normalizadores e do conhecimento pedagógico disponível e que justificam e legitimam a 
mudança que se almeja. Essas noções encontram eco na tese defendida por Correia (1989, p. 33), que, concordando com a necessidade de se distinguir os conceitos de inovação e de reforma, admite ser esta "uma inovação introduzida num macrossistema que pode facilitar a emergência de práticas inovadoras no(s) microssitema(s)". É nesse quadro que o autor distingue inovações instituidas e inovações instituintes. As inovações instituintes ou periféricas, ao contrário das instituidas, caracterizam-se por não se desenvolverem segundo

um processo completamente predeterminado e planificado nem se destinarem a ser generalizadas a todo o sistema (...) após a sua experimentação. Elas irrompem no interior de processos pré-programados não explicitando, muitas vezes, os seus objectivos ou as suas estratégias e são uma consequência do exercício de um poder instituído conquistado pelos professores ao Centro no contexto da institucionalização de uma reforma decidida pelo poder instituído (p. 36-37).

Pensando no domínio da educação, Correia (1989) admite que sempre que se implementa uma inovação instituida, concebida centralmente para ser aplicada uniformemente, há, por parte dos atores locais, a adoção de processos de resistência passiva traduzidos em procedimentos de aplicação no terreno o mais próximo possível das decisões tomadas centralmente. Ao contrário, no caso de inovações instituintes ou periféricas, há, por parte dos atores de terreno, a capacidade de fazerem uso da autonomia relativa de que dispõem, realizando um trabalho de (re)interpretação daquelas inovações, muitas vezes expresso em processos de resistência ativa, no sentido de as adaptarem aos contextos da sua intervenção. $O$ autor sintetiza estas ideias sustentando que é na dialéctica entre a inovação institui$d a$, concebida centralmente para ser generalizada a todas as instituições, e as práticas instituintes que recontextualizam a inovação que se "originam situações institucionalizadas singulares, dinâmicas e instáveis garantindo a manutenção de uma tendência à heterogeneização do sistema” (p. 38). No ponto seguinte deste texto, procuro relevar aspectos que evidenciem o lugar de destaque que é dado aos professores na construção de inovações curriculares e espelhar também possibilidades e constrangimentos inerentes a esses processos. 


\section{Os professores na construção de inovações curriculares}

Estudos realizados neste domínio apontam para a existência de uma polarização relativamente aos modos de olhar as inovações educativas e curriculares. De um lado, situam-se os que veem a resposta na regulação top-down do controle do currículo e das escolas, mediante uma avaliação externa dos resultados e, do outro, os que se empenham na autonomia, querendo encontrar a solução numa maior capacitação das escolas e dos professores (BOLÍVAR, 2003). Numa e noutra perspectiva, tem-se vindo a reconhecer "que é indispensável ganhar os professores para o esforço de mudança”" (FERNANDES, 2000, p. 76) e a relevar a ideia de que "independentemente de quão nobres, sofisticadas ou brilhantes possam ser as propostas de mudança e de aperfeiçoamento, elas nada representam se os professores não as adopta(re)m nas suas próprias salas de aula e não as traduz(ir)em numa prática profissional efectiva" (FULLAN; HARGREAVES, 2000, p. 29). Com efeito, é consensual a ideia de que os professores têm papel fundamental na construção de mudanças e de inovações curriculares, quer se trate de inovações instituidas (CORREIA, 1989) quer de propostas com caráter mais descentralizado ou, simplesmente, de propostas que emergem da periferia e que podem ser catalogadas de reais inovações instituintes.

Ao mesmo tempo, parece também haver consenso em relação ao fato de que nem todos os professores se posicionam da mesma forma perante propostas de inovação educacional e curricular ${ }^{7}$. Em relação a essa questão, Giroux (1988) considera que perante o apelo à inovação os professores se sentem simultaneamente ameaçados e desafiados. A ideia de ameaça é referenciada ao fato de continuar a ser ignorado, por parte dos decisores educativos, o conhecimento e as competências dos professores na análise crítica dos processos das inovações e dos seus objetivos. Em harmonia com esse pensamento, Stephen Ball (2002) assinala a ideia de os professores hoje trabalharem e agirem sem saberem muito bem o que se espera deles, "numa frustrante sucessão de números, indicadores de desempenho, comparações e competições, de tal maneira que a satisfação da estabilidade é cada vez mais ilusória" e na qual o princípio da incerteza se instala, criando "uma insegurança ontológica: Estamos a fazer o suficiente? Estamos a fazer o que é certo? Como conseguiremos estar à altura?" (p. 10) 
$\mathrm{Na}$ verdade, no contexto político atual, os professores portugueses vivem um clima de grande instabilidade emocional e profissional, advindo das diversas responsabilidades e exigências pedagógico-curriculares para que continuam a ser solicitados e pela avaliação de desempenho a que estão sujeitos, mas também por compromissos institucionais a que têm de responder, tendo em conta a importância hoje reconhecida de culturas de trabalho colaborativo e de práticas de autoavaliação, e o peso que tais dimensões têm quer na avaliação de desempenho dos professores ${ }^{8}$, quer na das escolas. Na realidade, os professores, para além de terem de lidar com a maior diversidade social e cultural dos alunos, e com capacidades de aprendizagens distintas, e de diversificar as situações de ensinoaprendizagem para responder a interesses e motivações diversas, têm também de "cuidar" do seu desempenho profissional, investindo na sua formação científica e na sua performance pedagógico-curricular, agora alvo de "inspeção" por parte dos pares pedagógicos responsáveis pela sua avaliação.

Esta ação em diferentes frentes está relacionada com os mandatos político-educativos e curriculares atribuídos à educação, à escola e ao currículo e com o modo como se entende a função e os papéis dos professores. Na década em análise neste texto (1997-2006), os papéis e funções dos professores portugueses têm sido marcados por orientações contraditórias, que ora os empurram para modos de trabalho assentes numa visão de inovação e de criatividade, ora os fazem recuar para modos de trabalho fortemente enraizados numa lógica técnico-burocrática e de grande conformidade com as diretrizes centrais da tutela. De permeio, os professores têm de saber gerir essas diferentes esferas de ação de modo a que não se sintam desqualificados profissionalmente e não deixem passar para a imagem pública uma representação de si como "maus profissionais". É nesse quadro de pressões que tem sido identificado o fenômeno de "mal estar docente" (CORREIA, 1997), traduzido, em muitos casos, em atitudes defensivas e de oposição à inovação e, noutros, em posturas de desânimo e de melancolia perante as múltiplas exigências de ordem burocrática e as responsabilidades pedagógico-curriculares a que têm de responder sob exíguas condições de trabalho e falta de tempo. Em consonância com esse pensamento, alguns estudos ${ }^{9}$ têm vindo a chamar a atenção para a permanente pressão social a que os professores têm estado sujeitos, fazendo deles bodes expiatórios de todos os problemas educa- 
tivos. Todavia, se, por um lado, os professores são perseguidos pelo estigma de "bodes expiatórios" dos males do sistema educativo, por outro, e como referi, são encarados como agentes criativos geradores de ações inovadoras e promotoras do sucesso da educação. Ou, dito de outro modo, são encarados como promotores de inovação curricular e educacional, promovendo interações positivas com as situações, os contextos e os sujeitos. Nessa direção, e no quadro dos novos desafios e exigências que lhes são colocados, há quem considere que eles desempenharão melhor o seu papel na construção de inovações se desenvolverem um conjunto de novas competências e capacidades, dentre as quais a capacidade de refletir e de questionar as situações e a capacidade de organizar, de modo coletivo e colaborativo, os processos pedagógio-curriculares (FULLAN, 1993). Esses diferentes pontos de vista sobre o papel de professor na construção da inovação curricular parecem representar uma ideia-síntese que aponta no sentido de que a mudança será mais facilmente alcançável e sustentada se comprometer todos os professores de uma comunidade educativa. Ora, essa ideia indica para uma nova profissionalidade pautada pelo exercício da partilha e da participação e ancorada num forte trabalho em equipe, na linha de uma profissionalidade ampla (HOYLE, 1980).

Fazer emergir e consolidar essa profissionalidade em sentido amplo, alicerçada numa cultura de trabalho em equipe, pressupõe, por um lado, olhar os contextos profissionais como espaços de formação dos professores (auto e heteroformação) e, por outro, conceber a escola como uma organização aprendente (FULLAN; HARGREAVES, 2000) e curricularmente inteligente (LEITE, 2003). Ou seja, uma escola que se desafia continuamente a si própria e que procura, envolvendo todos, instituir uma dinâmica interna conducente à melhoria das condições de trabalho dos professores e, consequentemente, à melhoria da qualidade da formação das crianças e jovens que acolhe. Esse desafio subentende, por parte de todos os professores e da própria escola, vontade de partilhar e de participar nessa procura conjunta de caminhos de inovação. Ora, tem sido na definição de uma plataforma comum de entendimento entre todos que têm sido identificados os maiores obstáculos e constrangimentos à mudança educacional. A esse propósito, aliás, importa ter em consideração as ideias de Perrenoud (2002, p. 100) quando lembra que "não se inova sozinho" e quando adverte para as dificuldades e resistências colocadas pelos professores em processos de parti- 
lha de saberes e de experiências e quando refere existirem situações em que um professor pode "ensinar vinte anos ao lado de um colega sem nunca ter falado com ele sobre pedagogia e sem saber mais sobre as suas práticas" (p. 96). Posição semelhante têm Fullan e Hargreaves (2000, p. 56) ao considerarem que "a situação mais comum para o professor não é ser parte de um grupo cooperativo, mas é a situação do isolamento, do trabalho solitário, longe dos colegas". Esse tipo de comportamento “dá aos professores uma espécie de protecção para colocar em prática (o) seu julgamento arbitrário, no interesse das crianças que eles conhecem melhor”. Em jeito de sistematização dessas visões, Mónica Thurler (1994, p. 33) afirma que as inovações curriculares dependerão sempre "daquilo que os professores pensarem dela(s) e delas(s) fizerem e da maneira como eles a(s) conseguirem construir activamente".

Essas ideias revelam-se significativas face ao foco da reflexão que pretendo acentuar neste texto, nomeadamente no que diz respeito às estratégias que os professores adotam perante inovações curriculares com origem externa às escolas, como foram o projeto de "Gestão Flexível do Currículo", a RCEB e a "Escola a Tempo Inteiro", sobre os quais se pronunciaram os professores/as que entrevistei e cujos discursos analiso no ponto seguinte deste texto.

\section{4. "Discursos diretos" de professores face a propostas curriculares para 0 ensino básico: que estratégias interpretativas?}

Justificando o(s) o referencial(ais) analítico(s) de base

Como na introdução a este texto referi, na análise aos discursos dos/as professores/as, segui o referencial de Doyle e Ponder (1977) quanto a estratégias adotadas por professores face a inovações curriculares com origem exterior à escola. Também como referi, para além deste referencial, apoiei a análise nos contributos de Correia (1989), no que respeita às ideias de inovação instituída e de inovação instituinte e às reações de resistência passiva e de resistência ativa dos professores que o autor a elas associa, respectivamente. O recurso, em simultâneo, a esses dois referenciais analíticos justificou-se por considerar que eles se complementam, no quadro da análise de discursos dos/as professores/as que entrevistei. 
Explicitando melhor a relação entre esses dois referenciais analíticos:

Doyle e Ponder (1977) identificaram três tipos de estratégias normalmente adotadas pelos professores face a inovações curriculares impostas ou propostas do exterior:

i) estratégia de adoção racional da inovação. Essa estratégia corresponde a uma postura de crença nos fundamentos ideológicos da inovação, resultando, assim, em interpretações positivas da mudança. Em analogia com as ideias de Correia (1989), os professores adotam, neste caso, processos de resistência passiva, traduzidos em procedimentos de aplicação no terreno o mais próximo possível das decisões tomadas centralmente;

ii) estratégia de obstrução recalcitrante da inovação. Trata-se, pois, de uma atitude de recusa latente da mudança, interpretada pelos professores de forma negativa, e que pode ser manifestada quer através de posicionamentos mais radicais de negação expressa dos professores ao que lhes é pedido pela tutela, quer de táticas mais "silenciadas" e que revelam também uma atitude demitente. Relacionando com as ideias de Correia (1989), uma e outra posição parecem não poder associar-se claramente aos conceitos de resistência passiva e ou de resistência ativa dos professores face à mudança, pois tal estratégia visa, em si, a apenas revelar o inconformismo dos professores no sentido de obstaculizar a inovação.

iii) estratégia de ceticismo pragmático da inovação. Nessa situação, os professores aderem temporariamente à inovação, cumprindo as diretivas e aplicando-as na prática, durante o período em que se sentem pressionados pela Administração Central, voltando às rotinas anteriores quando deixam de sentir essa influência. Numa relação com as ideias de Correia (1989), haverá, também temporariamente, por parte dos professores, processos de resistência ativa no sentido de adaptar a inovação aos contextos da sua intervenção.

\subsection{Primeiro momento de análise: o projeto de GFC e a RCEB - 1997-2003}

A análise dos discursos diretos dos/as professores/as entrevistados/as sobre o projeto de GFC e a RCEB evidencia, de um modo geral, interpretações positivas dessas medidas. Esse sentido positivo dos discursos é, igualmente, contraposto por um outro registro demonstrativo de reticên- 
cias quanto a efeitos concretos dessas propostas curriculares no trabalho dos professores e na vida das escolas.

Seguindo o referente analítico de Doyle e Ponder (1977), a análise permitiu identificar indicadores que apontam, em simultâneo, quer para estratégias de adoção racional da inovação, quer para um ceticismo pragmático. Tais indicadores revelam também que a primeira estratégia se reporta mais ao período inicial de implementação do projeto de GFC (1997 a 2001) e a segunda, ao período de finalização do mesmo, resultante da sua recomposição na RCEB (2001-2003), período em relação ao qual são também feitas interpretações negativas. Os excertos de discursos de professo$\mathrm{res} /$ as entrevistados/as atesta essa coexistência de estratégias:

O projecto de GFC veio trazer às escolas todas as a possibilidade de organizar o seu desenho curricular numa perspectiva de dar a resposta efectiva ao seu público-alvo. Nesta possibilidade eu acreditei e como eu, muitos outros professores (sujeito 2);

O projecto de GFC permitiu envolver as pessoas, deu-lhes mais possibilidades de reacção, de pensar, a execução é já mais personalizada e mais vivida por cada escola e de modo diferente (sujeito 1);

A flexibilização curricular foi uma oportunidade legal de legitimar ideias que já tínhamos e que queríamos pôr no terreno... O projecto de GFC introduziu novas visões sobre o currículo e isso foi muito importante para os professores aderirem... (sujeito 6).

Nesse mesmo período, os discursos mostram ter havido, por parte das escolas que "aderiram" ao projeto de GFC, a adoção de processos de resistência ativa (CORREIA, 1989), no sentido em que cada escola procurou encontrar os modos de gestão curricular mais adequados às suas especificidades e singularidades. Ao mesmo tempo, é também possível descortinar elementos que revelam ter havido, por parte dos professores, uma atitude de resistência passiva (CORREIA, 1989), isto é, de aplicação clara das diretrizes da tutela:

No início, no que diz respeito ao Estudo Acompanhado e à Área de Projecto, os professores cumpriram à risca as directrizes do Ministério da Educação (sujeito 10). 
O Projecto Educativo e o Projecto Curricular fizeram-se e fazem-se para cumprir o que está em lei... é preciso fazer, faz-se e está feito... e depois de feitos os professores descansam porque sentem que têm o dever cumprido (sujeito 8);

Com efeito, constata-se um posicionamento de adesão dos professores e de promoção nas escolas de iniciativas de gestão curricular (resistência ativa), num esforço de adequação do currículo nacional aos contextos e realidades específicas. Ao mesmo tempo, os discursos revelam que os professores tiveram também de responder a diretivas da tutela, cumprindo fielmente orientações para as quais eram solicitados (resistência passiva), como seja, por exemplo, a construção de Projetos Curriculares. Esses elementos discursivos corroboram o que em outro lugar sustentei, conjuntamente com Leite (LEITE; FERNANDES, 2002), quando analisámos reações de professores à RCEB em plena fase da sua implementação. Constatamos, então, a existência de atitudes que revelavam sentimentos de oposição/adesão aos princípios da RCEB e de legitimação de práticas que muitos professores vinham já desenvolvendo.

$\mathrm{Na}$ atual análise, e dentro do que designei de interpretações positivas dos professores sobre o projeto de GFC e a RCEB, identifiquei diferentes itens que expressam os sentidos dos discursos dos/as professores/as.

\subsubsection{Interpretações positivas dos professores sobre o projeto de GFC e a RCEB - 1997-2001}

No quadro destas interpretações positivas, identifiquei as seguintes "ideias-chave" que carregam os seguintes sentidos daquelas interpretações:

- crença no trabalho entre pares como dispositivo para uma nova dinâmica curricular

A este nível, a objetividade da visão positiva sobre o projeto de GFC é focada em aspectos de ordem prática, nomeadamente nos que se relacionam com oportunidades de os professores refletirem em conjunto e de tomarem decisões curriculares coletivamente e nos que se referem a mudanças ao nível dos modos de desenvolver o currículo e de trabalhar os conteúdos:

Quanto ao currículo, na prática, os professores mudaram muito na forma de trabalhar os conteúdos, ... temos caminhado no sentido dos princípios da 
gestão flexível do currículo... já não existe o ensino baseado na memorização. As mudanças são maiores ao nível das práticas (sujeito 3).

Foram muito importantes essas directrizes para cimentarem o trabalho em pares pedagógicos,... duas pessoas de áreas diferentes, com modos de trabalho diferentes, ... partilhar o espaço, partilhar ideias, preparar aulas, é muito importante (sujeito 5).

O Estudo Acompanhado e a Área de Projecto - vieram introduzir novas dinâmicas de trabalho entre os professores e ajudaram os alunos a desenvolverem-se na sua dimensão pessoal e social, ajudaram-nos a construir a pessoa do aluno (sujeito 6).

- crença na obtenção de competências técnicas para os/as professores/as, úteis para a construção de processos de gestão curricular

Entre os discursos imbuídos de um sentido positivo, é expressa a crença de que o movimento de gestão flexível do currículo produziu "ganhos" ao nível do desenvolvimento de competências técnicas, relacionadas com a elaboração de documentos como os Projetos Curriculares de Escola e os Projetos Curriculares de Turma. Este know-how técnico é bastante valorizado e identificado como um ganho que não se perdeu:

As medidas que foram introduzidas pelo projecto de GFC provocaram ganhos nas escolas que não se perderam. Pelo menos na formulação dos documentos os professores fizeram aprendizagens, adquiram a competência de conceberem projectos (sujeito 6);

A experiência desta escola foi um crescendo - No $1^{\circ}$ ano em que entrámos na GFC cometemos muitos erros... e fomos aprendendo com isso. Já lá vão 8 anos ... e há projectos curriculares de turma que ainda não cumprem talvez todos os objectivos fundamentais de um PCT, mas a maior parte deles já cumpre, e são projectos vividos, ... que são continuados (sujeito 4).

Essa informação é, mais uma vez, sintomática da existência de reações diferenciadas dos professores ao projeto de GFC e à RCEB e das capacidades que cada escola foi encontrando para acompanhar as solicitações da Administração Educacional. 


\subsubsection{Interpretações negativas dos professores sobre o projeto de GFC e a RCEB - 2001-2003}

Os discursos deixam transparecer interpretações negativas sobretudo quando se reportam ao período de transição do projeto de GFC para a RCEB (2001 a 2003) e ao tempo de governação PSD (2002-2004), durante o qual tais medidas e as experiências de gestão curricular em curso nas escolas foram quase totalmente ignoradas. Relativamente a esse contexto político, os discursos revelam interpretações indiciadoras de que muitos professores adotaram, sobretudo, estratégias de obstrução recalcitrante (DOYLE; PONDER, 1998) representativas de sentimentos de descontentamento face ao investimento feito:

Nós percorremos esse caminho nessa direcção... mas, porque não deu resultados visíveis hoje, nesta escola, as pessoas acharam que não era esse o caminho para este tipo de alunos (sujeito 10);

Os professores agora ${ }^{10}$ não querem construir currículos adaptados aos alunos, ... investiram muito no início e, agora, estão desgastados ... não veem resultados.... (sujeito 4).

Ainda neste campo das interpretações negativas sobre a RCEB, elas situam-se mormente no período de 2001 a 2003/2005. A análise detalhada que fiz dos discurso permitiu identificar os seguintes sentidos dessas interpretações:

\section{- descrença nas políticas de gestão curricular}

Alguns depoimentos indiciam interpretações de forte descrença quanto às políticas de gestão curricular e ao seu caráter inconsequente:

É evidente que com politicas avulsas, não é possível construir nada, ... é pura ilusão... os professores deixam de acreditar... e estão sempre à espera que mudem os governos porque já sabem que tudo voltará ao momento anterior (sujeito 6);

Eu acho que o pior de tudo é constantemente estar a sair nova legislação, novas medidas, umas ainda não foram implementados mas já outras estão a ser lançadas. Actualmente era necessário ponderar as consequências das medidas já implementadas... avaliar... fazer ajustes (sujeito 3); 
As constantes orientações do Ministério prejudicam o trabalho de equipas já organizadas - são imposições e, por isso, não são bem aceites” (sujeito 7);

O carácter inconsequente das políticas é um factor desmobilizador da mudança. Mudam os partidos, muda o ministério, muda logo a linha de orientação... e, portanto, ao longo destes 30 anos houve muitas mudanças que se foram fazendo sem se ter avaliado primeiro (sujeito 9).

A presença desses argumentos, para além de revelar um espírito não consentâneo com os princípios que estiveram subjacentes ao movimento de flexibilização curricular, empresta elementos que parecem legitimar a ideia de que os professores, de um modo geral, atuam, sob pressão da Administração, em conformidade com o que é prescrito centralmente e em proximidade com a estratégia de "ceticismo pragmático" (DOYLE; PONDER, 1997). Quando essa pressão desaparece, tudo parece voltar à "normalidade". Ao mesmo tempo, revelam que os professores, perante uma inovação curricular, ensaiam processos de resistência ativa (CORREIA, 1989), adaptando as diretivas centrais aos contextos e situações reais, acabando, por força da descontinuidade das políticas, por não dar seguimento a essas experiências de recontextualização curricular.

\section{- desejo de retorno a um paradigma de escola tradicional}

A interpretação de que "não valeu a pena" o investimento feito, e que é legitimadora de que os professores, no âmbito da RCEB (após o ano de 2001), adotaram processos de resistência ativa (CORREIA, 1989) e estratégias de ceticismo pragmático (DOYLE; PONDER, 1997), está bem presente nesse campo de interpretações negativas e provoca novos pensamentos que fazem associar o desejo de mudança à ideia de um retorno ao paradigma tradicional de escola:

$\mathrm{Na}$ verdade, uma ilação que posso tirar é a de que todo o investimento que fizemos não valeu a pena (sujeito10);

Houve a desvalorização do núcleo duro do currículo. ... se eu for avaliar eu penso que se perdeu, ao nível dos conhecimentos, eles são menos trabalhados... mas a formação integral do aluno, a esse nível melhorou (sujeito 1);

Neste momento, os professores não querem mais isto, querem voltar ao seu modelo de autoridade, querem ensinar a quem quer aprender, querem voltar ao modelo de escola anterior (sujeito 2); 
Nós estamos a sentir necessidade de voltar a dar mais importância, ... mais peso ao suporte académico, ao currículo académico...Os resultados académicos nos exames nacionais dos alunos estão na base do recuo a uma ideia de escola mais tradicional. Os alunos saem com o $9^{\circ}$ ano certificado mas sem competências... e isto tem a ver com a avaliação dos alunos porque soma tudo (sujeito7).

Interessante é perceber que o recuo a um paradigma de escola tradicional parece ser justificado pelos maus resultados acadêmicos dos alunos nos exames nacionais, o que deixa transparecer preocupações com a imagem social da escola

- atitude culpabilizadora das politicas e desculpabilizadora dos professores A ideia de desculpabilização dos professores e de culpabilização das políticas é central nos discursos associados a interpretações negativas sobre a RCEB e que se relaciona também com o período depois de 2002, aquando da transição do governo socialista para o governo social-democrata:

Este discurso político de que os professores têm a culpa de tudo não tem sido o mais feliz, não ajuda nada. Às vezes os professores sentem-se impotentes (sujeito 4);

Associam-se a essa visão argumentos que colocam também a ênfase nas políticas e lhes atribuem a culpa pela má qualidade da educação:

É nivelar por baixo. A organização do trabalho de turma tem muito em conta os mais fracos ... As políticas permitiram isto... a forma como elas podem ser interpretadas, na prática, no terreno, levaram a que chegássemos a esta situação ...e que se está a dar conta agora (sujeito 5);

O modo como têm sido implementadas as políticas curriculares tem contribuído para provocar fortes resistências... são umas alterações atrás das outras ... não houve espaço de reflexão, de avaliação (sujeito 8);

Há uma grande incoerência entre os princípios da gestão curricular e o sistema de avaliação. No fundo, nós continuamos a medir o currículo programático e as pessoas sentem uma grande pressão para preparem os alunos para responderem aos exames nacionais (sujeito 1).

Esses depoimentos espelham o sentido que atravessa a ideia de ciclo contínuo de politicas (BALL, 1992; 1994), no que respeita ao caráter 
ambíguo do texto legal e às possibilidades de os professores o interpretarem de acordo com seus interesses, fazendo "bom uso" dessa ambiguidade. Para melhor compreensão da análise feita aos discursos de professores/gestores sobre as interpretações que, em 2006, fazem do projeto de Gestão Flexível do Currículo e da Reorganização Curricular (RCEB), implementados entre1997e 2003, e também sobre o modo como sentiram que os professores das escolas que são responsáveis reagiram a essas medidas da política curricular, sistematizei essa informação no esquema 1. Nele apresento as ideias-síntese relativas às interpretações positivas e negativas devolvidas pela análise dos discursos e que melhor permitem objetivar os sentidos hoje atribuídos àquelas medidas.

Esquema 1. Estratégias e processos de resistência adotados por professores do Ensino Básico Português, face ao projeto de GFC e à RCEB - 1997-2003-, e interpretações que hoje fazem dessas medidas curriculares

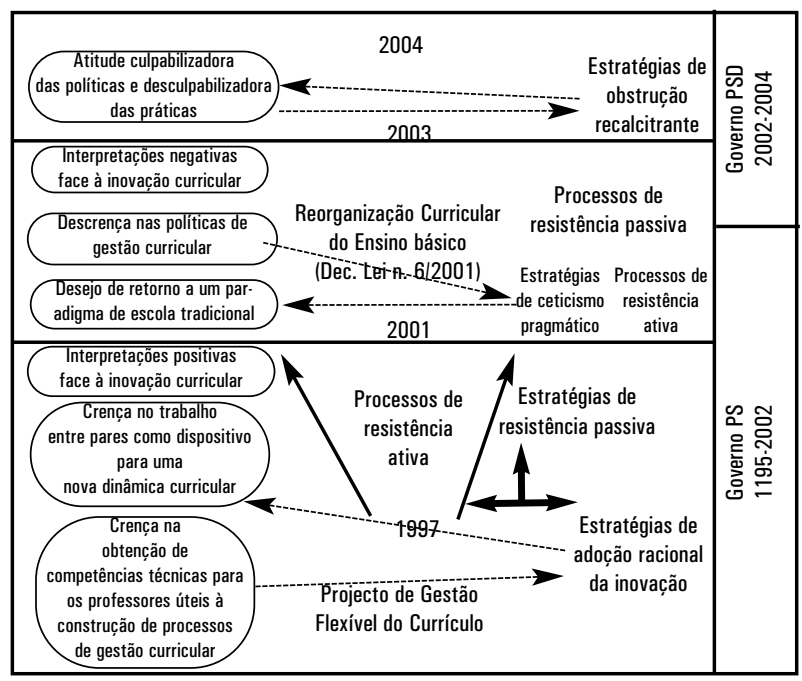

A representação esquemática permite observar que o período de 1997 a 2003-2004 correspondeu a um tempo marcado por oscilações, derivadas, por um lado, das metamorfoses intrínsecas às próprias medidas e, por outro, das mudanças de natureza política (do PS para o PSD), então verificadas. $\mathrm{O}$ esquema permite também notar a existência de um sentido evolutivo até 2001 que é expressivo da adesão gradual das escolas ao projeto de GFC - desde um número de dez escolas em 1997, até 180 escolas, em 2001. Como o esquema também exemplifica, nesse período, tal 
como referi, os professores reagiram diferenciadamente a essa inovação curricular.

Em 2001, essa proposta política perde o estatuto de projeto e passa a ser designada de Reorganização Curricular do Ensino Básico, regulamentada pelo Dec. Lei n. 6/2001. A partir desse ano, amplia-se, até 2003, a todas as escolas do ensino básico num formato "quadrado", igual para todas as escolas. Como ilustra o esquema, nesse período, os professores revelaram descontentamento com as alterações das políticas, adotando estratégias de obstrução recalcitrante ou, então, apenas cumprindo as diretrizes quando sujeitos à pressão do Ministério (ceticismo pragmático). Com a transição de governo do PS para o PSD, em 2002, assiste-se a um cerceamento dessa filosofia de gestão curricular, o que conduz também os professores a estratégias de obstrução recalcitrante, sentindo-se traídos e desrespeitados em relação aos projetos que tinham em curso ${ }^{11}$. O esquema mostra, assim, também o caráter inconsequente que marca as políticas curriculares nesse período em análise.

\subsection{Segundo momento de análise: A medida "Escola a Tempo Inteiro" - 2005-2006}

A ideia da inconsistência das políticas como "bode expiatório" para os males e fracassos da educação gane central nos discursos dos/as professores/as entrevistados/as, sobretudo quando se pronunciam sobre as medidas lançadas no ano letivo de 2005-2006, no âmbito da "Escola a tempo inteiro". Como expus, essa política curricular veio "incendiar" os cotidianos escolares, ao mexer com hábitos e rotinas instalados nas vidas pessoal e profissional dos professores e ao exigir deles, para além da complexificação de tarefas, maior tempo de permanência na escola. Esses são, aliás, argumentos interpretativos "de peso" usados pelos professores que entrevistei e que contrapõem com o argumento de que "ninguém está contra a escola aberta a tempo inteiro". A coexistência desses argumentos aponta para um posicionamento face à medida da política curricular "Escola a tempo inteiro", que pode ser situado entre as estratégias de ceticismo pragmático e de obstrução recalcitrante (DOYLE; PONDER, 1997). Na verdade, os discursos revelam posições de acordo com os princípios que estão na base da "Escola a tempo inteiro", e revelam também registros de completa oposição quanto à forma como aquela medida foi imposta pelo Ministério da Educação. 
Ninguém está contra a medida "Escola a tempo inteiro" desde que isso não implique mais horas de serviço, ou mais trabalho para os professores. A questão controversa e discutida não foi sobre a importância das actividades de enriquecimento curricular, o facto de estarmos a servir os pais ou estarmos a servir a comunidade, isso foi pacífico... O problema centrou-se sempre na carga horária que passaram a ter. Era para eles um direito adquirido que viram, neste momento, ser posto em causa (sujeito 8);

Nós concordamos com o princípio da escola a tempo inteiro, ...deve ser implementado mas não com os professores da componente lectiva, ...não fazem sentido nenhum as aulas de substituição, nem a permanência na escola de 35 horas semanais (sujeito 3).

\subsubsection{Interpretações negativas sobre a medida "Escola a tempo inteiro" - 2005- 2006}

Ainda que esses discursos possam ser situados nas posições antagônicas de concordância e de oposição, eles deixam, todavia, transparecer interpretações negativas e que podem ser traduzidas em estratégias de obstrução recalcitrante da inovação. Dentre essas interpretações negativas identifiquei os seguintes sentidos:

- intensificação do trabalho docente e receio de perda de direitos adquiridos Muitas interpretações que os/as professores/as fazem das medidas lançadas, no quadro da "Escola a tempo inteiro" e das alterações introduzidas pelo novo Estatuto da Carreira Docente, relacionam-se mais com receios de perdas de regalias e de direitos adquiridos e com questões ligadas com a intensificação do trabalho docente - resultante da obrigatoriedade de permanência de 35 horas semanais na escola - do que com os princípios que lhe estão na base, nomeadamente os que se relacionam com a melhoria da formação escolar dos/as jovens.

O problema centrou-se sempre na carga horária que tinham de fazer, as 35 horas semanais que passamos a ser obrigados a cumprir. Por outro lado, os professores nunca concordaram com o sistema das aulas de substituição...e isso revelou-se na atenção que deram às questões que estavam em jogo: pediram reuniões extraordinárias para se debater a carga horária distribuída e para demonstrarem discordância com as aulas de substituição, mas nunca pediram para discutir as questões relativas às actividades extracurriculares... e à sua importância na formação escolar dos jovens (sujeito 8). 
Como evidencia esse excerto, a centralidade da atenção está nos aspectos formais da medida e nas suas implicações na vida pessoal e profissional dos professores. Dele parece poder inferir-se ter havido, de fato, por parte de alguns professores, a adoção de estratégias de obstrução recalcitrante (DOYLE; PONDER, 1997) expressa em atitudes de reivindicação de direitos adquiridos e de não-aceitação de novas diretrizes.

\section{- injustiça para com o trabalho dos professores}

A interpretação de que "ninguém está contra" a medida "Escola a tempo inteiro" é, como referi, contraposta com outras interpretações que revelam reações de forte resistência e que fazem desviar aquela proposta dos efeitos desejados pela tutela. São, de fato, vários os discursos em que os/as entrevistados/as se pronunciam sobre as reações negativas dos professores das escolas que gerem, face a todas as alterações ocorridas no âmbito da medida "Escola a tempo inteiro":

Foi difícil... houve um certo mal-estar por parte dos professores...Sentemse altamente injustiçados porque as medidas impostas pela ministra são na maioria práticas correntes cá na escola, há muito tempo...Este ano, foi uma catástrofe... Nunca houve tantas faltas. As mais recentes políticas vieram estragar a cultura da escola, o ethos... para quem já estava habituado... as pessoas sentiram-se descomprometidas em relação à ocupação dos alunos (sujeito 2);

As medidas não caíram nada bem, ... os professores não gostaram dos modos como a Ministra as impôs... sentem que o seu trabalho não é minimamente reconhecido... sentem-se injustiçados (sujeito 7);

Desconfiança, descontentamento...o grande problema foram mesmo as aulas de substituição, foi um caos nesta escola. Os professores que raramente faltavam e agora revoltaram-se (sujeito 3).

Esses excertos denunciam, de fato, a utilização de estratégias de obstrução recalcitrante como bloqueio à concretização das diretrizes da tutela, nomeadamente as relacionadas com as aulas de substituição.

\section{- posição deliberada de contorno da lei}

Os juízos negativos manifestados por muitos/as professores/as face à medida "Escola a tempo inteiro" e às aulas de substituição, em particular, obrigaram alguns órgãos de gestão a deliberar mecanismos de con- 
torno da lei e a encontrar respostas internas que satisfizessem, primeiro, os professores e, segundo, respondessem ao estipulado na lei. O estipulado na lei aponta para o $1^{\circ}$ ciclo do ensino básico manter os alunos nas escolas até as cinco horas em atividades de enriquecimento curricular, e para os $2^{\circ}$ e $3^{\circ}$ ciclos organizarem e programarem atividades educativas que proporcionem aos alunos o aproveitamento pleno dos tempos decorrentes de ausência imprevista do respectivo docente (aulas de substituição). Essas manobras revelam uma atitude de resistência ativa (CORREIA, 1989) por parte dos professores/gestores, expressa na capacidade de deliberar, protegendo os interesses dos professores, e de adaptar as diretivas centrais, interpretando-as, aos contextos e situações reais.

Conseguimos implementar um conjunto de outras actividades para ocupação dos alunos e funcionou muito bem ...e, assim, não mexemos com os horários dos professores, ... procurámos seleccionar os professores mais vocacionados para esses projectos e articular-nos com associações locais que asseguraram grande parte das actividades de enriquecimento curricular (sujeito 4);

Não foi posto em causa o trabalho da escola, tivemos que contornar a legislação,.. porque é para bem do bom ambiente da escola ...não queremos professores de mal com a escola (sujeito 7).

Ao mesmo tempo, esses testemunhos corroboram a ideia que está subjacente ao ciclo contínuo de políticas (BALL, 1992) referente às possibilidades de interpretação a que a política curricular está sujeita nos diferentes contextos (influência, produção e prática) pelos atores que neles intervêm. Por outro lado, reforça a ideia anteriormente avançada de que os professores sabem tirar partido do lado ambígu da lei. Esse fato parece ainda contribuir para clarificar o raciocínio de que as escolas e os professores têm autonomia para interpretar os diplomas legais em nome de um "bem-estar coletivo", a que muitos recusam chamar de "corporativismo".

\subsubsection{Interpretações positivas sobre a medida "Escola a tempo inteiro" - 2005- 2006}

- concordância com as políticas versus discordância com as reações dos professores

Ainda que, em geral, a tendência dos discursos revele interpretações de descontentamento para com as medidas da política curricular, 
alguns/mas dos/as entrevistados, na qualidade de gestores educativos, analisam esse desagrado com um sentido dissonante do dos professores das escolas que gerem. Alguns desses argumentos mostram um sentido interpretativo de concordância com as políticas e, simultaneamente, de discordância com a reação de alguns professores.

É impossível alguém fazer alguma coisa na escola estando lá apenas $14 \mathrm{~h}$ como era até aqui...como podem ser inovadores vindo aqui, dando apenas as suas aulinhas aos seus meninos e ir embora... (sujeito 6);

Para alguns professores, ... estas medidas até fazem sentido (sujeito 3 ).

Deixam, por outro lado, transparecer a necessidade de os professores precisarem de ser impulsionados centralmente para a mudança para que não se cristalizem hábitos e rotinas profissionais, revelando, assim, um posicionamento, por parte de quem lidera e gere as escolas, de aceitação da inovação que pode ser entendido quer como uma estratégia de adoção racional da mudança, quer como uma estratégia de ceticismo pragmático (DOYLE; PONDER, 1977).

Eles estão entristecidos com as directrizes que vêm do ministério mas eu acho que eles deviam estar entristecidos com eles... qualquer profissional, ... deve estar entristecido sempre que o seu trabalho não está a ter bons resultados, não é? ...então, deviam ser os primeiros a tentar mudar algo... porque reagem sempre mal às propostas do Ministério, ... porque não aproveitam as oportunidades para gerar novas experiências (sujeito 1);

Os professores reagem sempre, ... faz parte da sua cultura profissional e o que deviam era aproveitar estas medidas para ensaiarem a sua autonomia... respondendo de forma positiva às propostas do Ministério, adaptando-as aos seus contextos, aos seus alunos e às suas práticas (sujeito 8).

Também essa última posição imputa aos professores responsabilidades pelo seu desempenho e brio profissional e denuncia a importância de eles saberem aproveitar as oportunidades para se afirmarem e afirmarem sua autonomia na construção local de processos de inovação curricular. Essas posições de advertência evocam, por outro lado, a importância de se prever a inovação curricular numa perspectiva dialética que alie diretrizes pensadas a nível central com possibilidades da sua recontextualização no contexto da prática (BALL, 1992), possibilidades essas que podem ser 
associadas a processos de resistência ativa (CORREIA, 1989) dos professores. Para uma melhor clarificação, sistematizei as estratégias adotadas por professores face às medidas da política curricular inseridas no âmbito da "Escola a tempo inteiro" no esquema 2. Nele intento ainda tornar visíveis interpretações que delas fazem hoje os professores que entrevistei, tendo em conta sua opinião e a percepção que têm sobre o modo como os professores das suas escolas reagiram a essas mesmas medidas.

Esquema 2. Estratégias e processos de resistência adotados por professores do Ensino Básico Português face à medida da política curricular

"Escola a tempo inteiro" (2005-2006) e interpretações que fazem dessa proposta

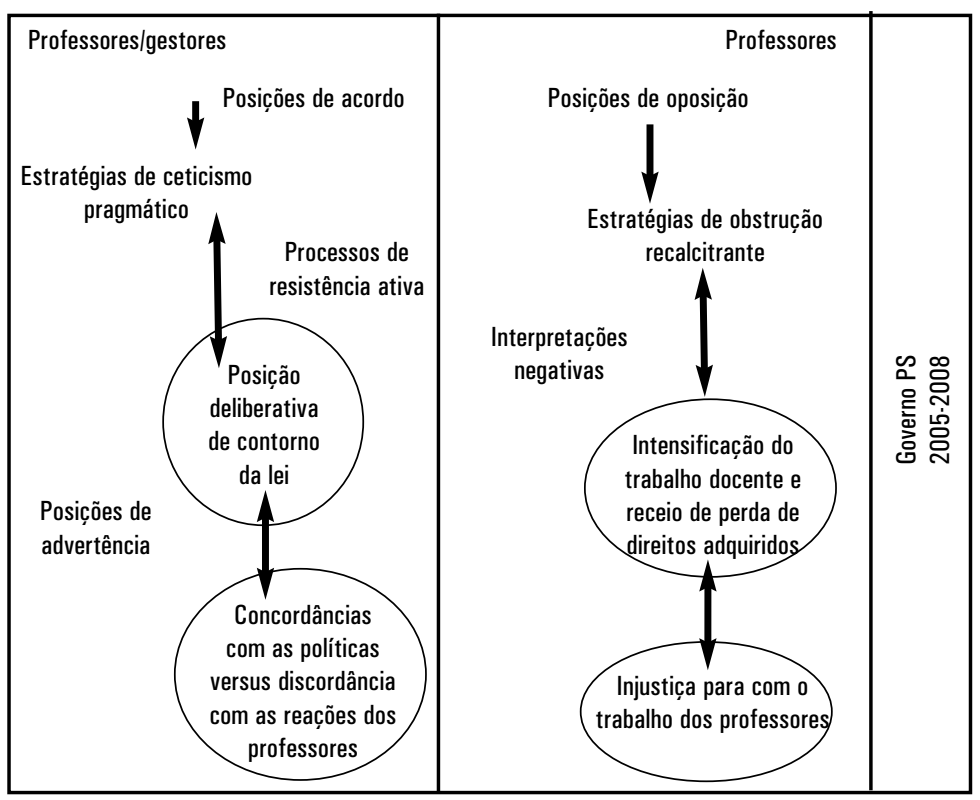

Como ilustra o esquema n. 2, os discursos relativos à medida "Escola a tempo inteiro", implementada no período de 2005-2006, mostram que houve posições de acordo e de completa oposição: as primeiras são expressas pelos professores em exercício de gestão educacional e as segundas referem-se à visão destes relativamente aos professores das escolas que gerem. Em Portugal, esse foi um período vivido com grande agitação pela maioria dos professores, expressa em grandes manifestações públicas e greves nacionais, revelando inequivocamente estratégias de obstrução recalcitrante (DOYLE; PONDER, 1977) face à medida curricular 
"Escola a tempo inteiro". As interpretações negativas que a maioria dos professores fez daquela medida política relacionaram-se com reivindicações de caráter profissional e tiveram implicações diretas na vida das escolas, levando a que muitos gestores procurassem, enquanto elos de concretização das políticas da equipe ministerial, "manter uma postura de serenidade", adotando, assim, estratégias de ceticismo pragmático (DOYLE; PONDER, 1977) que garantissem algum sucesso na aplicação da inovação "no terreno". Como ao longo da análise salientei, em algumas situações tiveram mesmo de, cautelosamente, perfilhar estratégias de contorno da lei, num esforço de solidariedade com seus pares e de os manterem minimamente satisfeitos e empenhados na profissão. Mesmo assim, outros gestores não deixaram de fazer interpretações de advertência quanto aos comportamentos adotados por alguns professores. Esses diferentes juízos sobre a medida "Escola a tempo inteiro" são bem ilustrativos do clima que nesse período se viveu nas escolas portuguesas e dos sentimentos de "mal-estar docente" manifestados pela maioria dos professores.

\section{Considerações finais}

Como ao longo do texto fui referenciando, as interpretações que os/as professores/as fazem das propostas curriculares para o ensino básico, lançadas no período de 1997-2006, em Portugal, revelam tendências que podem, genericamente, ser situadas entre visões de crença/descrença e de concordância/oposição com essas políticas. No que diz respeito ao período 1997-2003, os registros de crença reportam-se mormente ao período de implementação do projeto de GFC (até 2001) e, nesse contexto também, os impactos positivos são referentes a mudanças ocorridas ao nível das concepções curriculares e do desenvolvimento de competências técnicas. Por outro lado, embora os discursos evidenciem registros que revelam que o projeto de GFC e a RCEB criaram condições nas escolas para o trabalho conjunto entre os professores e para práticas curriculares com caráter interdisciplinar, todavia eles manifestam que esse não foi um resultado com sustentabilidade, fato que justifica também a ainda não-existência de uma cultura profissional colaborativa (HARGREAVES, 1998) nas escolas portuguesas. Com efeito, as ideias de professor configurador do currículo e de gestão curricular que ganharam força no contexto do projeto de 
GFC, foram-se desvanecendo sobretudo a partir da regulamentação da RCEB, em 2001, e do alargamento a todas as escolas do ensino básico até 2003, e com as sucessivas alterações que, entretanto, se fizeram sentir nas políticas curriculares. Efetivamente, em 2004, com a transição de um governo socialista, mentor de uma política curricular assente em princípios de flexibilização e de gestão local do currículo, para um governo social-democrata, essa filosofia de flexibilização do currículo, inserida numa orientação de descentralização das políticas educacionais e de atribuição de maior autonomia aos atores locais na tomada de decisões curriculares, deixou de ter a centralidade nos discursos oficiais que até então tinha tido.

Em consequência, os anos de 2005-2006, no que diz respeito ao contexto da prática e, particularmente, a processos de organização e de desenvolvimento do currículo, traduzem certo "desgoverno pedagógicocurricular": numa mesma escola coabitam diferentes modos de olhar a inovação e diferentes modos de se posicionar curricularmente, o que necessariamente conduz a diferentes modos de pensar a autonomia e as decisões curriculares. A análise que fiz aos discursos dos professores face à medida "Escola a tempo inteiro", implementada em 2005-2006, revelou que as questões pedagógico-curriculares não foram centrais para muitos professores. Ao contrário, e como também revelou a análise, nos espaços coletivos em que os professores criaram manifestações de protesto sobre aquela medida da política curricular, o enfoque foi colocado em questões relacionadas com a defesa da profissão e da sua imagem social, nomeadamente as que se prendiam com o alargamento do horário de permanência na escola e com as aulas de substituição, e nesta relação, com receios em perderem direitos adquiridos.

Já no ano lectivo de 2008, tal tendência foi-se desfocando e outras preocupações surgiram, agora relacionadas com um novo modelo de avaliação de desempenho dos professores. Ainda não refeitos das alterações ocorridas no âmbito da medida "Escola a tempo inteiro", a avaliação do desempenho, no quadro das modificações introduzidas no novo Estatuto da Carreira Docente (Dec. Lei. n. 15/2007 de 19 de janeiro), os professores são confrontados com alterações que colocam em jogo seu estatuto profissional e a progressão na carreira. Essas mudanças revolucionaram de novo os contextos escolares_e os impactos_que estão a ter no terreno parecem fazer-se sentir sobretudo ao nível de um retorno a uma 
cultura profissional individualista e competitiva que lhes assegure uma performance profissional que garanta a boa avaliação do seu desempenho profissional.

Em síntese, a análise que fiz aos dos discursos de professores/as /gestores/as sobre inovações curriculares para o ensino básico, lançadas no ano de 2005/2006, em Portugal, revela, em simultâneo, a existência de posturas de concordância/oposição. Os/as entrevistados revelam sentimentos de concordância com as políticas, especialmente quando expressam seu ponto de vista. Os elementos discursivos reveladores de oposição são expressos quando esses/as gestores/as se pronunciam, particularmente, sobre o modo como os professores das escolas de que são responsáveis viveram e reagiram àquelas medidas. Referem, nesse âmbito, que os professores se sentem descontentes com as políticas impostas pelo Ministério da Educação e se sentem também injustiçados por o seu trabalho não ser reconhecido pela tutela.

Uma outra ideia-síntese da análise revela que a descontinuidade nas políticas curriculares constitui um fator obstaculizador à construção de práticas de inovação curricular e à edificação de uma cultura profissional colaborativa. Perante as constantes alterações das políticas e a mudança permanente de direção a que são abruptamente sujeitos, os professores reconhecem "não valer a pena" os investimentos feitos na construção de processos de gestão curricular e expressam desejo de voltar ao modelo de "escola tradicional". Subjacente a esse desejo está também a ambição em ganharem "de novo" a centralidade e a autoridade que admitem terem "perdido".

Resumindo, a pesquisa revelou que o "lado micro" da política curricular espelha bem os impactos da macropolítica "no terreno da prática", pelo que importará que os "atores de terreno" sejam reconhecidos como sujeitos centrais nas decisões da política curricular e nelas seja incorporado o conhecimento aprofundado que têm das realidades concretas. Acredito, pois, que esse possa ser um caminho para o maior comprometimento de todos os professores em processos de inovação educacional e curricular. 


\section{REFERÊNCIAS}

APPLE, Michael. Educación y poder. Barcelona: Paidós, 1987.

BALL, Stephen. The policy process and the processes of policy. In BOWLE, Richard; BALL, Stephen; GOLD, A. (Orgs.). Reforming education \& changing Scholl: case studies in policy sociology. London/New York: Routledge, 1992. p. 6-23.

BALL, Stephen. Educational reform: a critical and post-structural approach. Buckingham: Open University Press, 1994.

BALL, Stephen. Directrizes políticas globais e relações políticas locais em educação. Currículo Sem Fronteiras, v. 1, n. 2, jul/dez, p. 99-116, 2001.

BALL, Stephen. Reformar escolas/reformar professores e os terrores da performatividade. Revista Portuguesa de Educação, v. 15, n. 2, p. 3-23, 2002.

BENAVENTE, Ana. A reforma educativa e a formação de professores. In: NÓVOA, A.; POPKEWITZ, Thomas (Org.). Reformas educativas e formação de professores. Lisboa: Educa, 1992. p. 47-55.

BOLÍVAR, António. Como melhorar as escolas. Porto: Edições Asa, 2003.

BOWE, R.; BALL, Stephen; GOLD, A. Reforming education and changing schools: case studies in policy sociology. London: Routledge, 1992.

CANÁRIO, Rui; ALVES, Natália; ROLO, Clara. Escola e exclusão social. Lisboa: IIE, 2001. CORREIA, José Alberto. Inovação pedagógica e formação de professores. Porto: Edições Asa, 1989.

CORREIA, José Alberto. Formação e trabalho: contributos para uma transformação dos modos de os pensar na sua articulação. In: CANÁRIO, Rui (Org.). Formação e situações de trabalho. Porto: Porto Editora, 1997.

CORREIA. José Alberto; MATOS, Manuel. Solidões e solidariedades nos quotidianos dos professores. Porto: Edições Asa, 2001.

CORTESÃO, Luíza. Ser professor: Um ofício em vias de extinção? Reflexões sobre práticas educativas face à diversidade, no limiar do século XXI. Porto: Edições Afrontamento, 2000.

DOYLE; PONDER. The practically ethic in teacher decision-making. Interchange, n. 8, p. 1-12, 1977.

FERNANDES, Margarida. Mudança e Inovação na Pós-modernidade. Perspectivas curriculares. Porto: Porto Editora, 2000.

FERNANDES, Preciosa. Da reforma curricular do Ensino Básico dos finais dos anos 80 à reor ganização curricular dos finais dos anos 90: uma análise focalizada nos discursos. In LEITE, Carlinda (Org.). Mudanças curriculares em Portugal. Transição para o século XXI. Porto: Porto Editora, 2005. p. 51-73.

FULLAN, Michel; HARGREAVES, Andy. A escola como organização aprendente. Buscando uma educação de qualidade. Porto Alegre, 2000.

GIMENO SACRISTÁN. Consciência da acção sobre a prática como libertação profissional dos professores. In: NÓVOA, António (Org.). Profissão de professor. Porto: Porto Editora, 1991. p. 63-92.

GIROUX, Henry. Teachers as intellectuals: Toward a critical pedagogy of learning. New York: Bergin \& Garvey, 1988.

HOYLE, Eric. Professionazation and deprofessionalization in education. In: HOYLE, Eric; MEGARRY Jacquetta (Eds.) Professional Development of Teachers. World Yeabook of 
Education 1980. Londres: Kogan, 1980. p. 42-54.

LEITE, Carlinda. O currículo e o multiculturalismo no sistema educativo português. Lisboa: Fundação Calouste Gulbenkian, 2002.

LEITE, Carlinda. Para uma escola curricularmente inteligente. Porto: Edições Asa, 2003.

LEITE, Carlinda; FERNANDES, Preciosa. Potencialidades e limites da gestão local do currículo para (e na) construção de uma escola com sentido para todos. In ME/DEB Gestão Flexivel do Currículo. Reflexões de formadores e investigadores. Lisboa: DEB, 2002. p. 41-62.

PERRENOUD, Philippe. Pedagogia diferenciada. Porto Alegre: Artmed, 1999.

PERRENOUD, Philippe. Aprender a negociar a mudança em educação. Novas estratégias de inovação. Porto: Edições Asa, 2002.

THURLER, Mónica. Levar os professores a uma construção activa da mudança. Para uma concepção da gestão da inovação. In: THURLER, Mónica; PERRENOUD, Philippe. A escola e a mudança. Lisboa: Escolar, 1994. p. 33-59. 


\section{NOTAS}

$1 \mathrm{O}$ ensino básico corresponde ao $1^{\circ}, 2^{\circ}$, e 3 . Ciclos do Ensino Básico (até $4^{\circ}$ ano de escolaridade; $5^{\circ}$ e $6^{\circ}$ ano de escolaridade, ; $7^{\circ}, 8^{\circ}$ e $9^{\circ}$ anos de escolaridade, respectivamente).

2 Regulamentada pelo Despacho n. 12 591/2006 (2a série), revogado pelo Despacho n. $14460 / 2008$

3 A implementação do projeto de "Gestão Flexível do Currículo" teve início, em 1997, com o processo de reflexão participada dos currículos do ensino básico proposto pelo Ministério da Educação a todas as escolas, em que professores foram estimulados a refletir e propor sugestões relativamente à organização curricular. Essas reflexões e conclusões constam de um relatório elaborado pelo DEB.

4 No âmbito deste projecto, as escolas foram estimuladas pela Administração Central a apresentar um Projeto de Gestão Curricular local. As escolas que aderiram foram paulatinamente construindo o "seu caminho", numa direção que foi ganhando "sentidos" peculiares em cada uma delas, conforme suas especificidades, quer ao nível dos seus problemas, quer da cultura de trabalho colegial já existente (ou não), quer das dinâmicas de trabalho e dos próprios recursos, etc.

5 Ver, a este propósito, Fernandes (2005).

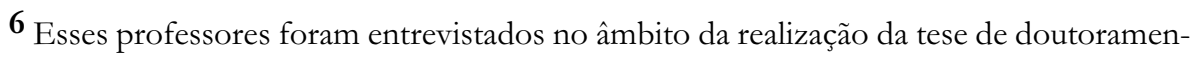
to que terminei em 2007.

7 Ver, a este propósito, entre outros, Fulan e Hargreves (2000), Leite (2002), Leite e Fernandes (2002).

8 A avaliação de desempenho dos professores é a terminologia utilizada no Novo Estatuto da Carreira Docente, regulamentado pelo decreto-lei 15/2007, de 19 de janeiro e o modelo da sua implementação foi regulamentado pelo Decreto n. 2/2008, de 10 de janeiro.

9 Veja-se, por exemplo, Cortesão (2000), Gimeno (1991), Hargreaves (1998), Perrenoud (1999, 2002), Leite (2002), Correia e Matos (2001).

10 A recolha destes discursos foi feita no decurso do ano 2007.

11 Em jeito ilustrativo, refiro a experiência dos agrupamentos horizontais, em que muitas escolas se envolveram de forma muito implicada e responsável e que passados dois anos, em 2002, foram obrigados a reorganizarem-se em estruturas verticais, que passaram a incluir escolas dos $2^{\circ}$ e $3^{\circ}$ ciclo. Todo esse processo foi feito em total desacordo com os professores envolvidos na primeira experiência e que viram ignorado todo o trabalho feito e o conhecimento produzido nesse domínio. 
Recebido: 12/01/2010

Aprovado: 15/09/2010

Contato:

Rua Doutor Manuel Pereira da Silva, 4200-392

Porto - Portugal 